\title{
Correspondence
}

\section{Acute assessments in psychiatry}

As a core trainee in psychiatry, I feel the issue of trainees working out of hours is vitally important.

With changes to rotas as described by Conn \& Husain, trainees find themselves not having to do acute crisis assessments and instead, nurse-led assessments are becoming more common. These factors have a huge impact on psychiatry as a specialty. Junior doctors on certain rotas are not involved in the decision-making process for admission and are simply used as clerking machines responsible for completing paperwork and a physical examination once the patient is admitted. No other specialty works in this way; all acute non-psychiatric referrals are seen by doctors and a full assessment is carried out, including discussion with senior medical personnel, before the management plan is finalised.

I feel that patients needing acute psychiatric assessments usually present with multiple problems and comorbidities which require the doctor's input to ensure a holistic approach and that organic factors are taken into account. During my first core training year, the experience I got with acute assessments helped considerably to develop my skills in assessing and managing risk and dealing with acute presentations.

The image of psychiatry among numerous medical students whom I have been involved in teaching, and that revealed in recent surveys, is that 'psychiatry is an easy option'. ${ }^{2}$ I feel it is time that psychiatry stands up and shows what it has to offer. This needs trainees to get involved in assessments and take responsibility to ensure that psychiatry has a future.

1 Conn R, Husain M. Trainees want to work out of hours! Psychiatrist 2013; 37: 117.

2 Archdall C, Atapattu T, Anderson E. Qualitative study of medical students' experiences of a psychiatric attachment. Psychiatrist 2013; 37: 21-4.

Abid H. Choudry, СT2 Trainee, Dudley and Walsall Mental Health Partnership NHS Trust, Birmingham, UK, email: abidchoudry@ doctors.org.uk

doi: 10.1192/pb.37.7.244

\section{A message to psychiatry trainees: keep your finger on the pulse}

In light of the recent Royal College of Psychiatrists' report on achieving parity between mental and physical health, the paper by Yadav \& Vidyarthi ${ }^{2}$ came as a timely illustration of the need for trainees to take responsibility for their continuing professional development and the role of the College.

Patients put their faith in doctors of all specialties to look after them. In an acute situation they implicitly trust us to be able to perform investigations, interpret the results correctly, and act appropriately to instigate swift and appropriate management. In the UK, the overarching duties of a doctor are laid out by the General Medical Council. ${ }^{3}$ One such duty is to 'keep your professional knowledge and skills up to date, recognise and work within the limits of your competence, and work with colleagues in a way that best serves the patient's interest'. This is echoed in the Royal College of Psychiatrists'
Good Psychiatric Practice. We hope most trainees would agree with Craddock et al ${ }^{4}$ who believe that psychiatrists are 'first and foremost highly trained doctors'.

Admittedly, the specialty suffers from esteem issues, but if we want to be respected as doctors we must commit to continued professional development to improve the care for our patients. The NHS Outcomes Framework hopes to improve professionals' attitudes towards patients. Are we not discriminating against our own patients if we fail to take responsibility for keeping our clinical skills up to date?

We reviewed the CANMEDS competencies framework, which is used by a number of varied specialties both in the UK and abroad. 'Medical expert' is a key domain. This is not to suggest a trainee must be 'expert' in, say, reading electrocardiogram (ECG) results, but rather that they should be able to integrate knowledge, clinical skills and professional behaviours in order to provide excellent care for their patients. The College has carefully mapped the CANMEDS competencies on to its curriculum for core trainees. However, we caution that there is not a clear expectation or way of assessing trainees' medical skills.

In contrast, the core curriculum for core medical trainees comprehensively addresses the knowledge, skills and behaviours required to manage psychiatric emergencies. As well as acute medical presentations, core medical trainees must also demonstrate competencies in the following presentations: suicidal ideation, aggressive/disturbed behaviour, acute confusion/delirium, and alcohol and substance dependence. Furthermore, there is clarification of what they should demonstrate. For example, every core medical trainee should 'be competent in predicting and preventing aggressive and disturbed behaviour, using safe physical intervention and tranquillisation [ . . . ] and investigating appropriately and liaising with the mental health team' (p. 77). ${ }^{5}$

Psychiatry trainees frequently complete a workplacebased assessment on electroconvulsive therapy. Perhaps performing an ECG or physical examination and interpreting the findings may be sensible competencies. It is heartening that the Royal College of Psychiatrists seem to recognise the need for trainees to maintain essential medical knowledge. There are some very good College CPD Online modules such as 'Taking a general medical history in psychiatry' and the appositely named 'Don't shrink from ECG'. We welcome the planned expansion of the free CPD modules and anticipate there may be more on medical themes. The December 2012 diet of the MRCPsych Paper 1 featured a question on ECG interpretation. Some trainees found this controversial, but others would regard this as a pass/fail question.

We therefore argue that the current psychiatry core curriculum could better address the medical competencies required in sufficient detail to motivate all trainees to attain and maintain their skills. Let's work with and learn from our medical colleagues.

1 Royal College of Psychiatrists. Whole-Person Care: From Rhetoric to Reality. Achieving Parity Between Mental and Physical Health (Occasional Paper OP88). Royal College of Psychiatrists, 2013. 
2 Yadav R, Vidyarthi A. Electrocardiogram interpretation skills in psychiatry trainees. Psychiatrist 2013; 37: 94-7.

3 General Medical Council. Good Medical Practice. GMC, 2001

4 Craddock N, Antebi D, Attenburrow M-J, Bailey A, Carson A, Cowen P, et al. Wake-up call for British psychiatry. Br J Psychiatry 2008; 193: 6-9.

5 Joint Royal Colleges of Physicians Training Board. Specialty Training Curriculum for Core Medical Trainees. JRCPTB, 2009 amended 2012. (http://www.jrcptb.org.uk/trainingandcert/Documents/ 2009\%20CMT\%20framework\%20(revised\%20Aug\%202012).pdf).

Alison S. Lennox, CT1 in psychiatry, Oxford Health NHS Foundation Trust, Oxford, UK, email: alison.lennox@oxfordhealth.nhs.uk; Ben A. S. Wildblood, CT1 in medicine, North Bristol NHS Trust.

doi: $10.1192 / \mathrm{pb} .37 .7 .244 a$

\section{Why commissioners need to know about Section 136}

The article by Patrick Keown ${ }^{1}$ was a timely contribution to discussions currently taking place about the use of Section 136 between the Royal College of Psychiatrists, Home Office, Department of Health, Police, Health and Social Care Information Centre, and Care Quality Commission. A major and long-standing problem in understanding the trends in the use of this power has been the failure to collect complete information on the use of Section 136, as the author points out, referring to data collected in 2005-2006. We would like to draw attention to more recent data collected in 2011-2012: these show a dramatic increase in rates of detention under Section $136-43 \%$ in 6 years, from 16500 to 23569 . $^{2}$ Although the number taken to custody suites has fallen from 11500 (2005-2006) to 8667 (2011-2012), this figure still far exceeds the anticipated number if custody suites were used in 'exceptional circumstances only', as described in the Mental Health Act 1983 Code of Practice, $^{3}$ and reiterated in the Royal College of Psychiatrists' guidance. ${ }^{4}$

In 2012, the Association of Chief Police Officers (ACPO) collected information on the use of Section 136 in all 43 police areas and discovered that $37 \%$ of those detained under Section 136 continue to go to a custody suite, although this varies between force areas. Despite approximately $£ 130$ million of capital funding having been made available for Section 136 suites 7 years ago, there are several police forces in England that still do not have access to hospital places of safety 24 hours a day and/or when demand exceeds capacity. This unacceptable variability in provision is clearly a commissioning issue and in March this year the College produced guidance for local commissioners in order to help identify shortfalls in local service provision. ${ }^{4}$

The multi-agency Mental Health Act group chaired by the College is collecting more detailed information on local services and would be delighted to receive completed surveys (www.rcpsych.ac.uk/pdf/PS02_2013_survey.pdf) from members to inform further discussions.

1 Keown P. Place of safety orders in England: changes in use and outcome, 1984/5 to 2010/11. Psychiatrist 2013; 37: 89-93.

2 Health and Social Care Information Centre. Inpatients Formally Detained in Hospitals Under the Mental Health Act 1983 and Patients Subject to Supervised Community Treatment - England, 2011-2012, Annual Figures. HSCIC, 2012 (http://www.hscic.gov.uk/catalogue/PUB08085).

3 Department of Health. Mental Health Act 1983 Code of Practice. TSO (The Stationery Office), 2008.
4 Royal College of Psychiatrists. Guidance for Commissioners: Service Provision for Section 136 of the Mental Health Act 1983 (Position Statement PS2/2013). Royal College of Psychiatrists, 2013.

Julie S. Chalmers, Consultant Psychiatrist, The Elms Centre, Banbury, and Honorary Senior Clinical Lecturer, University of Oxford, email: Julie.Chalmers@oxfordhealth.nhs.uk; Michele Hampson, Specialist Advisor, Mental Health Law, Royal College of Psychiatrists, London, UK.

doi: $10.1192 / p b .37 .7 .245$

\section{Getting it right for people with dementia}

Steve llife's editorial is perceptive, diplomatic and hopefully not too late. ${ }^{1}$ As he makes clear, dementia is not, for most people, a stand-alone condition. Once established it remains significant in determining quality of life and need for help and support right to the end of an individual's life. Every journey with dementia is unique and will not be constrained by a predictive pathway or tidied into convenient once-and-for-all time phases.

Our model of specialist involvement in primary care in Gnosall Memory Service, which is dismissed as third choice by psychiatrists in the South West, has the advantage of proven sustainability over nearly 7 years. The arrangements bring the specialist expertise of psychiatry into the practice and the practice retains the clinical responsibility for patients. Many are elderly and carry a number of illnesses for which they attend the practice: a memory problem is simply one of a spectrum of challenges, and attendance at a practice clinic is an acceptable addition to the patient's routine. Patients are seen as people with full lives with important social and family involvement. An integrated and collaborative approach achieves rapid access to assessment, diagnosis and care planning, with high satisfaction by all parties and reduced usage of other components of the mental health and general hospital economies. ${ }^{2-4}$

The Gnosall experiment was not intended to remain an isolated enterprise: several visiting teams have taken the essentials of the model and begun similar services elsewhere. We have described a three-tier model which foresees the integration of the work in primary care within a reorganised district memory service as a component of the old age psychiatry service. $^{5}$

We are currently working with commissioners, South Staffordshire and Shropshire Healthcare NHS Foundation Trust, and a federation of over 30 primary care outlets that cover 360000 patients, with a view to implementing this vision over a wider area. This is not a pathway to loss of special skills, independence or status, but the logical way to deliver a sensitive, comprehensive and affordable service for every individual and every family with dementia in the UK in the 21st century.

Declaration of interest

All authors contribute to the work of the Gnosall Memory Service.

1 lliffe S. Commissioning services for people with dementia: how to get it right. Psychiatrist 2013; 37: 121-3.

2 Greening L, Greaves I, Greaves N, Jolley D. Positive thinking on dementia in primary care: Gnosall Memory Clinic. Community Pract 2009; 82: $20-3$.

3 Greaves I, Jolley D. National Dementia Strategy: well intentioned but how well founded and how well directed? Br J Gen Pract 2010; 60: 193-8. 